\title{
Management of infants with large, unrepaired ventricular septal defects and respiratory infection requiring mechanical ventilation
}

\author{
Mahesh Bhatt, MD \\ Stephen J. Roth, MD, MPH \\ R. Krishna Kumar, MD, $D^{a}$ \\ Kimberlee Gauvreau, $S_{c} D^{d}$ \\ Suresh G. Nair, MD ${ }^{\mathrm{b}}$ \\ Suresh Chengode, MD ${ }^{\mathrm{b}}$ \\ Krishnanaik Shivaprakasha, MS, MCh ${ }^{\mathrm{c}}$ \\ Suresh G. Rao, MS, $\mathrm{MCh}^{\mathrm{c}}$
}

From the Departments of Pediatric Cardiology, ${ }^{\mathrm{a}}$ Anesthesiology, ${ }^{\mathrm{b}}$ and Pediatric Cardiac Surgery, ${ }^{c}$ Amrita Institute of Medical Sciences and Research Centre, Kochi, Kerala, India, the Department of Cardiology, ${ }^{\mathrm{d}}$ Children's Hospital Boston, and the Department of Pediatrics, Harvard Medical School, Boston, Mass.

Received for publication Aug 11, 2003; revisions requested Oct 10, 2003; accepted for publication Nov 6, 2003.

Address for reprints: R. Krishna Kumar, MD, DM, Amrita Institute of Medical Sciences and Research Centre, Kochi 682026, Kerala, India (E-mail: rkrishnakumar@ aimshospital.org).

J Thorac Cardiovasc Surg 2004;127: $1466-73$

$0022-5223 / \$ 30.00$

Copyright (๑) 2004 by The American Association for Thoracic Surgery

doi:10.1016/j.jtcvs.2003.11.030
Objectives: We sought to describe the hospital management and early outcome of critically ill infants presenting with large ventricular septal defects and pneumonia requiring mechanical ventilation at a referral center in a developing country. Infants with large ventricular septal defects who have pneumonia might present with respiratory failure requiring mechanical ventilation. In the developing world this presentation is relatively common, but few data exist describing patient management strategies.

Methods: Hospital data of consecutive infants admitted with large ventricular septal defects and pneumonia requiring mechanical ventilation were reviewed and analyzed.

Results: We identified 18 infants (mean age, $3.6 \pm 3.0$ months). On admission, all the infants were significantly malnourished, and echocardiography showed bidirectional shunting (predominantly right-to-left shunting) in 6 infants. Thirteen (72\%) patients improved with intensive medical management that included mechanical ventilation for 1 to 16 days (median, 6.5 days); unequivocal left-to-right shunting was subsequently documented by means of echocardiography in all 13 patients. Twelve patients underwent surgical repair, and 11 (91.6\%) were discharged after median mechanical ventilation of 100 hours (range, 42-240 hours) and intensive care unit stay of 8 days (range, 4-15 days). Five of 6 unoperated patients died, 4 of them within a few hours of admission. One child with multiple ventricular septal defects was discharged and subsequently underwent pulmonary artery banding.

Conclusion: Corrective cardiac surgery for selected critically ill infants with large ventricular septal defects, severe malnutrition, and pneumonia requiring mechanical ventilation is feasible and should be considered a viable management strategy.

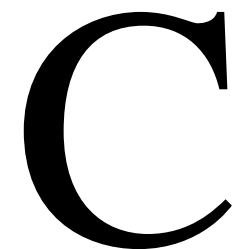
ongenital heart defects with large left-to-right shunts commonly present in infancy with respiratory symptoms and poor growth. ${ }^{1}$ Among the various shunt lesions that present in infancy, ventricular septal defect (VSD) is the most common. A left-to-right shunt can adversely affect lung function, ${ }^{2}$ and superimposed lower respiratory tract infections cause additional compromise and might lead to respiratory failure, necessitating mechanical ventilation. ${ }^{3}$ Malnutrition and delayed presentation in the developing world further compound disease severity. ${ }^{4}$ Once mechanical ventilation is initiated, it is often difficult to wean and extubate these 
patients without correcting their underlying cardiovascular pathophysiology. Extubation failure with prolonged mechanical ventilation leads to other complications, such as nosocomial infection, and higher mortality.

The treatment approach for infants and young children with large VSDs and pneumonia who present with respiratory failure requiring mechanical ventilation is not well defined, even though this presentation is relatively common in the developing world. Often, there is significant reluctance to operate on these critically ill patients because of concerns about additional organ dysfunction associated with cardiopulmonary bypass (CPB). ${ }^{6,7}$ Furthermore, a transient increase in pulmonary vascular resistance (PVR) resulting from lung infection and impaired gas exchange might result in right-to-left shunting, which creates uncertainty in determining the optimal timing of surgical intervention. This report, from a large tertiary referral center in South India, describes the hospital management and early outcome of a consecutive series of 18 critically ill infants with large VSDs and pneumonia requiring mechanical ventilation.

\section{Methods}

\section{Study Design and Patient Population}

We reviewed the hospital records of all consecutive infants admitted to our institution between September 1998 and October 2002 with VSDs and pneumonia requiring treatment with mechanical ventilation. Patients with associated coarctation of the aorta and those undergoing VSD closure as a part of a more complex cardiac procedure (eg, arterial switch or the Rastelli operation) were excluded. Infants with VSDs and associated atrial septal defects, patent ductus arteriosus, or both were not excluded. Preoperative lung infection was defined as the presence of at least 4 of the following 5 findings: fever (temperature $>38^{\circ} \mathrm{C}$ ), signs of respiratory distress, signs of lower respiratory tract infection on auscultation (rales, bronchial breath sounds, or wheeze), total leukocyte count of greater than 15,000 cells $/ \mathrm{mm}^{3}$, and radiographic evidence of lung infection. Permission for chart review was obtained from the hospital's medical records department.

\section{Setting}

The study was conducted in a tertiary care hospital with an established pediatric cardiovascular program catering to a population of approximately 30 million persons in the state of Kerala in southern India.

\section{Initial Supportive Management in the Intensive Care Unit}

All patients underwent a comprehensive clinical evaluation on admission to the intensive care unit (ICU). Laboratory investigations included a complete blood count, erythrocyte sedimentation rate assessment, liver and renal function tests, bacterial cultures of blood and tracheal secretions, electrolyte measurement, arterial blood gas analyses, electrocardiography, chest radiography, and echocardiography. Respiratory secretions were not tested for viral pathogens. Empiric intravenous antibiotics were selected on the basis of the antibiotic sensitivity profiles of the most common bacterial pathogens cultured from patients who were admitted to the ICU with respiratory infections. Changes in the antibiotic regimen were made on the basis of antibiotic sensitivity profiles. Mechanical ventilation was instituted for one or more of the following reasons ${ }^{8}$ :

1. Increased work of breathing with impending respiratory failure;

2. heart failure not responding to maximal pharmacologic support; and

3. acute respiratory failure with significant hypercarbia, hypoxemia, or both despite supplemental oxygen.

\section{Evaluation of Cardiac Lesion and Operability}

The diagnosis of the underlying cardiac lesion or lesions and the decision to operate were based on clinical evaluation and echocardiography in most patients. If the initial echocardiogram showed significant right-to-left color Doppler flow across the defect, serial echocardiograms were performed to monitor the direction of shunt flow. Typically, as pulmonary function improved with treatment, shunting across the defect or defects became predominantly left to right. Cardiac catheterization was performed if a sustained increase in PVR was suspected (persistent right-to-left color Doppler flow across the defect or persistent systemic desaturation despite evidence of resolving respiratory infection).

\section{Decision to Operate}

Early in our experience, we attempted to wean the patient from mechanical ventilation by using standard guidelines if the patient showed clinical improvement in the first 48 hours. ${ }^{9}$ As experience accrued, we attempted to perform corrective surgical intervention at the earliest safe opportunity, which was determined by improving clinical and ventilatory parameters. Although we desired complete resolution of respiratory infection before cardiac surgery, in view of patient symptom severity, we considered the following minimum requirements to be necessary to proceed with surgical intervention:

1. absence of fever for 48 hours or longer;

2. decreasing leukocyte counts, if initially increased, and increasing platelet counts, if initially reduced;

3. at least partial radiologic clearance of lung infiltrates;

4. improved arterial blood gases $\left(\mathrm{PaO}_{2}>60 \mathrm{~mm} \mathrm{Hg}\right.$ and $\mathrm{PaCO}_{2}$ $<50 \mathrm{~mm} \mathrm{Hg}$ on a fraction of inspired oxygen of $<0.4$ using pressure-controlled ventilation with maximum peak inspiratory pressures of $30-35 \mathrm{~mm} \mathrm{Hg}$ and tidal volumes of 10 $\mathrm{mL} / \mathrm{kg}$ ); and

5. unequivocal documentation of predominant left-to-right systolic shunting on color Doppler echocardiography.

Documentation of negative bacterial cultures and normalization of gas exchange, although desirable, were not mandatory.

\section{Cardiac Surgery}

Twelve of 18 patients improved such that cardiac surgery with standard surgical techniques and CPB was performed. ${ }^{10}$ Specific modifications of our routine intraoperative methods included the use of near-normothermic bypass, every attempt to reduce bypass and total support times, and the use of ultrafiltration to achieve an optimal fluid balance and to reduce pulmonary interstitial edema, myocardial edema, or both after the operation. ${ }^{11,12}$ The decision to 
leave the sternum open after the operation depended on hemodynamic stability after weaning from bypass. The catheters that were routinely placed for postoperative monitoring included an arterial, a central venous, and a pulmonary arterial catheter.

\section{Postoperative Care}

Clinical status, hemodynamic stability, arterial blood gas results, radiologic appearance of the lung fields, and respiratory effort dictated the duration of mechanical ventilation. All patients were ventilated in a pressure-regulated, volume-controlled mode. Pressure-controlled ventilation and inverse ratio ventilation were used when the pressure-regulated, volume-controlled mode did not improve oxygenation. Standard guidelines for weaning and extubation were used and consistently applied. ${ }^{13}$

Worsening gas exchange immediately after extubation was managed by means of noninvasive ventilation with a small silicone facemask (Respironics), with a harness modified for infants. Either a Servo 300 ventilator (Siemens) or a specialized noninvasive ventilator (BIPAP Vision, Respironics) that delivered biphasic positive airway pressure was used to provide continuous positive airway pressure or pressure support ventilation.

The standard vasoactive drug in the postoperative period was dopamine $\left(2.5-10 \mu \mathrm{g} \cdot \mathrm{kg}^{-1} \cdot \mathrm{min}^{-1}\right)$. Epinephrine $(0.01-0.05 \mu \mathrm{g}$ $\cdot \mathrm{kg}^{-1} \cdot \min ^{-1}$ ) was used occasionally when tissue hypoperfusion persisted after maximum doses of dopamine.

Pulmonary hypertensive crises were managed with hyperventilation to a $\mathrm{PaCO}_{2}$ of 30 to $35 \mathrm{~mm} \mathrm{Hg}$, nebulized salbutamol, and deeper levels of sedation or anesthesia, together with muscle relaxation. Inhaled nitric oxide and phenoxybenzamine were administered if these initial measures were ineffective.

Antibiotic choice in the postoperative period was guided by the same principles described previously plus blood and tracheal culture results. Antibiotics were administered for a total period of 14 days or until no further evidence of infection was apparent. Infants with evidence of fulminant sepsis and profound leukopenia underwent a double-volume exchange transfusion with fresh whole blood. ${ }^{14}$ Postoperative nutrition was accomplished by means of early initiation of calorie-dense nasogastric feeds.

\section{Follow-up}

All patients who were successfully discharged after repair were followed up at 1 month and then at 3-month intervals.

\section{Statistical Analysis}

We sought to compare the hospital course of the 12 ventilated infants with VSDs and pneumonia who underwent repair with that a similar group of infants undergoing elective VSD closure at our institution during the study period. This control group of 12 infants who were not ventilated before surgical intervention was selected from our surgical database. The surgical database was sorted for age and body weight, and control subjects were randomly selected from 3 age categories ( $1-3$ months, $>3$ months and $<6$ months, and 6-12 months) that matched the study population. Continuous demographic, operative, and postoperative variables were compared between the 2 groups by using the 2 -sample $t$ test or the Wilcoxon rank sum test, as appropriate. The Fisher exact test was used for categoric variables.

\section{Results}

\section{Study Population}

During the study period, 18 infants were admitted with VSD and pneumonia requiring mechanical ventilation. The mean $z$ score for weight of these 18 infants was $-3.02 \pm 1.34$ on the basis of National Center for Health Statistics standards; 9 infants had $z$ scores of less than $-3.00 .^{15}$

\section{Resuscitation and Stabilization in the ICU}

Four patients who had an acute respiratory arrest and one patient with presumed hypoxic seizures required tracheal intubation on admission, whereas 12 others were intubated for mechanical ventilation because of deteriorating arterial blood gases or impending respiratory failure. One patient was intubated and mechanically ventilated at a referring hospital. All 18 patients had clinical and radiologic evidence of significant respiratory infection.

\section{Preoperative Hemodynamics}

All patients had unrestrictive VSDs with severe pulmonary hypertension. Six patients had bidirectional shunting (predominant right-to-left shunting) at presentation. In all of these patients, serial color Doppler echocardiographic studies showed that the shunt became predominantly left to right after the respiratory infection improved. One patient underwent cardiac catheterization for determination of PVR and candidacy for correction (Table 1, patient 7); this patient subsequently underwent surgical repair.

Management with mechanical ventilation and intravenous antibiotics resulted in clinical improvement in 13 of 18 patients such that cardiac surgery was performed in 12 after a median of 6.5 days of ventilatory support (range, 1-16 days). In these patients the mean $\mathrm{PaO}_{2}$ improved from 63.9 $\pm 24.7 \mathrm{~mm} \mathrm{Hg}$ on admission to $99.6 \pm 24.2 \mathrm{~mm} \mathrm{Hg}$ before repair, whereas the mean $\mathrm{PaCO}_{2}$ improved from $64.5 \pm 15.6$ $\mathrm{mm} \mathrm{Hg}$ to $42.7 \pm 8.4 \mathrm{~mm} \mathrm{Hg}$. The mean total white blood cell count decreased from $19,000 \pm 7800 / \mathrm{mm}^{3}$ at admission to $11,600 \pm 4100 / \mathrm{mm}^{3}$. All had improvement in the lung fields on chest radiography, although complete resolution of pneumonia occurred in only one patient.

\section{Surgical Repair and Postoperative Course}

The 12 patients who underwent VSD closure during the study period represented $5 \%$ of all infants undergoing VSD closure at our institution $(n=234)$ during the study period. The mean CPB time was $101 \pm 32$ minutes, and the mean aortic crossclamp time was $54 \pm 18$ minutes.

There was one death after surgical intervention. The patient was a 2-month-old infant weighing $2.5 \mathrm{~kg}$ (Table 1 , patient 8) who died from severe low cardiac output 3 hours after the operation. Low cardiac output was possibly related to a long intraoperative support time required to close multiple VSDs (CPB time of 148 minutes and crossclamp time of 78 minutes, the longest among all patients). 
TABLE 1. Clinical details and outcomes of individual patients

\begin{tabular}{|c|c|c|c|c|c|c|c|c|c|}
\hline $\begin{array}{l}\text { Patient } \\
\text { no. } \\
\end{array}$ & $\begin{array}{l}\text { Age } \\
\text { (mo) }\end{array}$ & $\begin{array}{c}\text { Weight } \\
\text { (kg) }\end{array}$ & Diagnosis & $\begin{array}{l}\text { Blood } \\
\text { culture }\end{array}$ & $\begin{array}{l}\text { Lowest } \\
\mathrm{PaO}_{2} \\
(\mathrm{~mm} \mathrm{Hg})\end{array}$ & $\begin{array}{c}\text { Maximum } \\
\mathrm{PaCO}_{2} \\
(\mathrm{~mm} \mathrm{Hg})\end{array}$ & $\begin{array}{l}\text { Duration of } \\
\text { ventilation } \\
\text { (d) }\end{array}$ & Operation & Outcome \\
\hline 1 & 2 & 3 & VSD & GNB & 91 & 65 & 7 & VSD closure & Discharged \\
\hline 2 & 4 & 2.6 & VSD & GNB & 68 & 65 & 14 & VSD closure & Discharged \\
\hline 3 & 6 & 4 & VSD & Staph & 49 & 60 & 4 & VSD closure & Discharged \\
\hline 4 & 3 & 4 & VSD & GNB & 48 & 60 & 15 & VSD closure & Discharged \\
\hline 5 & 6 & 4.5 & VSD & $N G$ & 35 & 58 & 6 & VSD closure & Discharged \\
\hline 6 & 1 & 3.4 & VSD & GNB & 30 & 63 & 16 & VSD closure & Discharged \\
\hline 7 & 1 & 3.7 & VSD & GNB & 34 & 61 & 6 & VSD closure & Discharged \\
\hline 8 & 2 & 2.5 & VSD & $N G$ & 103 & 45 & $<1$ & VSD closure & $\begin{array}{l}\text { Death after } \\
\text { prolonged CPB }\end{array}$ \\
\hline 9 & 8 & 3.8 & VSD & $N G$ & 73 & 97 & 8 & VSD closure & Discharged \\
\hline 10 & 1.5 & 3.5 & VSD & $N G$ & 83 & 40 & 7 & VSD closure & Discharged \\
\hline 11 & 5 & 5.1 & VSD & NG & 73 & 77 & 3 & VSD closure & Discharged \\
\hline 12 & 2 & 3.75 & VSD & $N G$ & 82 & 83 & 1 & VSD closure & Discharged \\
\hline 13 & 8 & 2.2 & VSD & GNB, Strep & 66 & 49 & 8 & No & $\begin{array}{l}\text { Death caused by } \\
\text { sepsis }\end{array}$ \\
\hline 14 & 2 & 3.6 & VSD & Not done & 49 & 151 & $<1$ & No & $\begin{array}{l}\text { Death caused by } \\
\text { respiratory } \\
\text { failure }\end{array}$ \\
\hline 15 & 1.5 & 2.4 & VSD & $N G$ & 46 & 55 & $<1$ & No & $\begin{array}{l}\text { Death caused by } \\
\text { respiratory } \\
\text { failure }\end{array}$ \\
\hline 16 & 0.3 & 1.8 & VSD & Not done & 98 & 47 & $<1$ & No & $\begin{array}{l}\text { Death caused by } \\
\text { VF }\end{array}$ \\
\hline 17 & 5 & 2.9 & VSD & Not done & Not done & Not done & $<1$ & No & $\begin{array}{l}\text { Death caused by } \\
\text { respiratory } \\
\text { failure }\end{array}$ \\
\hline 18 & 4 & 4.4 & $\begin{array}{l}\text { Multiple } \\
\text { apical } \\
\text { muscular } \\
\text { VSDs }\end{array}$ & $\begin{array}{r}\text { GNB + } \\
\text { Staph }\end{array}$ & 83 & 55 & 10 & No & $\begin{array}{l}\text { Discharged (PAB } \\
3 \text { months later) }\end{array}$ \\
\hline
\end{tabular}

VSD, Ventricular septal defect; GNB, gram-negative bacilli; Staph, Staphylococcus aureus; NG, no growth; CPB, Cardiopulmonary bypass; Strep, Streptococcus fecalis; $V F$, ventricular fibrillation; $P A B$, pulmonary artery band. PVR, pulmonary vascular resistance.

Among the 11 survivors, the median duration of postoperative ventilation was 100 hours (range, 42-240 hours). Three patients required reintubation. Nine patients received noninvasive ventilatory support for a mean of $26 \pm 6$ hours after extubation. The median ICU stay was 8 days (range, 4-15 days). Six patients had positive postoperative bacterial cultures with the same organisms that were cultured preoperatively. The 11 survivors were discharged after a median postoperative hospital stay of 14 days (range, 9-36 days). Three patients required delayed sternal closure (mean, 28.1 \pm 18.3 hours) because of unfavorable postbypass hemodynamics. Two of them had pulmonary hypertensive crises and positive postoperative bacterial cultures. All 3 recovered with treatment and were discharged after 13 to 36 days. Other morbidities in the immediate postoperative period included low cardiac output state $(\mathrm{n}=5)$, arrhythmias $(\mathrm{n}=$ $4)$, and persistent lung infection $(n=6)$. There were no instances of wound infection or mediastinitis. Echocardiography at discharge showed no significant residual lesions and a reduction in pulmonary artery pressure to less than half of the systemic value in all patients.

\section{Hospital Course of Unoperated Patients}

Six patients did not undergo repair (Figure 1 and Table 1, patients 13-18). Four could not be stabilized and died within a few hours of hospitalization (Table 1, patients 14-17). All 4 had extensive pneumonia and severe congestive cardiac failure, and all required immediate intubation for respiratory arrest at admission. One patient, who died after 8 days of mechanical ventilation, was an 8-month-old, profoundly malnourished child $(2.2 \mathrm{~kg} ; z$ score, -6.4$)$ with a large VSD, gastroenteritis, and bacterial sepsis (Table 2, patient 13). The lone survivor among the group was a 4-month-old patient with multiple muscular VSDs who was extubated successfully after 10 days, discharged, and then underwent placement of a pulmonary artery band 3 months later (Table 1 , patient 18). The outcome of all 18 patients is summarized in Figure 1. 


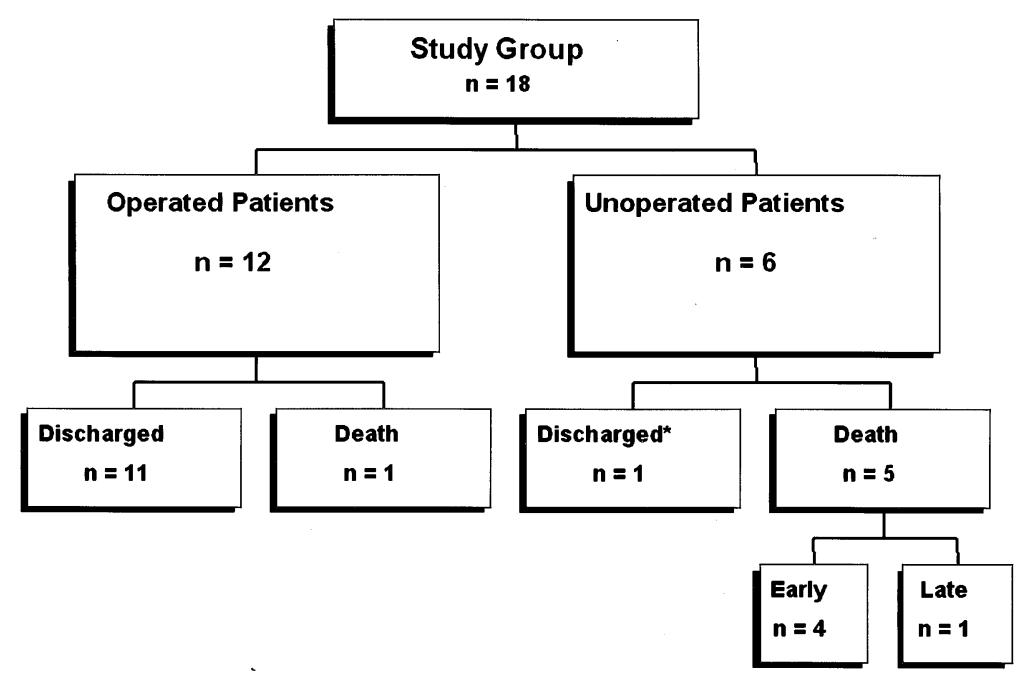

Figure 1. This flow chart summarizes the early outcome of study infants with VSDs and pneumonia requiring mechanical ventilation. Among unoperated patients who died, early refers to death within 24 hours of ICU admission, and late refers to death later in the ICU course. *This patient eventually underwent a pulmonary artery band.

TABLE 2. Comparison of perioperative characteristics of the study group (ventilated patients) with a control cohort of nonventilated patients undergoing elective VSD closure

\begin{tabular}{|c|c|c|c|}
\hline Patient characteristics & $\begin{array}{l}\text { Ventilated patients } \\
\text { (n= 12) }\end{array}$ & $\begin{array}{l}\text { Nonventilated patients } \\
\qquad(\mathrm{n}=12)\end{array}$ & $P$ value \\
\hline Age (mo) & $3.6(2.1)$ & $4.0(1.5)$ & $N S^{*}$ \\
\hline Weight (kg) & $3.6(0.8)$ & $3.8(0.8)$ & $N S^{*}$ \\
\hline Weight $z$ score & $-2.8(1.0)$ & $-2.7(1.0)$ & $N S^{*}$ \\
\hline Size of VSD (mm) & $9.1(3.9)$ & $8.2(2.2)$ & $\mathrm{NS}^{*}$ \\
\hline Location of VSD & $\begin{array}{l}\text { Perimembranous in } 10, \\
\text { subpulmonic in 1, } \\
\text { posterior muscular } \\
\text { in } 1\end{array}$ & Perimembranous in all & NS \\
\hline Cardiopulmonary bypass time (min) & $101(32)$ & $92(21)$ & $N S^{*}$ \\
\hline Aortic crossclamp time (min) & $54(18)$ & $45(13)$ & $N S^{*}$ \\
\hline Postoperative mechanical ventilation (h) & $100(42-240)$ & $24(16-72)$ & $<.001^{* *}$ \\
\hline Postoperative ICU stay (d) & $8(4-15)$ & $3(2-6)$ & $<.001^{* *}$ \\
\hline Postoperative hospital stay (d) & $14(9-36)$ & $8(7-12)$ & $<.001^{*}$ \\
\hline Postoperative weight gain in $3 \mathrm{mo}(\mathrm{g})$ & $2620(950)$ & $2440(770)$ & $N S^{*}$ \\
\hline
\end{tabular}

All values with a normal distribution are expressed as mean (SD) and those with a wide range are expressed as median (range).

$V S D$, Ventricular septal defect; ICU, intensive care unit; $N S$, not significant.

*Two-sample $t$ test.

**Wilcoxon rank sum test.

\section{Follow-up}

All 11 infants who survived surgical correction had postdischarge follow-up between 1 and 24 months. Growth assessments revealed evidence of catch-up growth, with a mean weight gain of $2.85 \pm 0.93 \mathrm{~kg}$ in 3 months. Cardiac evaluation by means of clinical examination and echocardiography revealed no shunt lesions and normal pulmonary artery pressures. The patient who had a pulmonary artery band is symptom free 1 year after palliation, with reduction in the size of the VSDs.

\section{Comparison with Infants Undergoing Elective VSD \\ Closure}

When compared with infants who underwent elective VSD closures at our institution, this group of ventilated infants had longer durations of mechanical ventilation, ICU stay, 
and hospital stay (Table 2). Both groups had comparable intraoperative support times.

\section{Discussion}

The clinical scenario of a cardiac lesion with a large leftto-right shunt plus extensive respiratory infection in malnourished infants is relatively common in the developing world. ${ }^{16}$ These infants often present in critical condition and require mechanical ventilatory support.

\section{Treatment Options}

For a sick ventilated infant with a large VSD and severe pneumonia, one of the following 3 management strategies could be pursued: (1) medical management and corrective surgical intervention during the same hospitalization; (2) medical management, hospital discharge, and, assuming survival, subsequent elective surgical repair; or (3) medical management and palliative surgical intervention with pulmonary artery banding during the same hospitalization.

Many physicians in the developing world would favor the second or third management strategy. Concerns about subjecting critically ill infants with active lung infection to $\mathrm{CPB}$ arise from fears of exacerbating lung inflammation and unleashing the underlying infection because of immune suppression. ${ }^{17,18}$ Complement, kinins, endotoxin, proinflammatory cytokines, tumor necrosis factor $\alpha$, and activated leukocytes and platelets are all presumed to mediate lung injury and alter cellular and humoral immune responses that would exacerbate the pathology of a patient with pneumonia. ${ }^{19,20}$

Preoperative mechanical ventilation has been identified as an independent risk factor associated with a complicated postoperative course. ${ }^{7}$ Pulmonary complications frequently cause delayed recovery after cardiac surgery in young children. ${ }^{6,21}$ The majority of centers in developing countries have relatively limited human and material resources that prevent them from adopting an aggressive policy of early correction of heart defects in young infants, especially those who are most compromised. The limited resources available are often allocated to patients with the potential for better outcomes.

We adopted a policy of early surgical correction (the first strategy above) because we believed that prolonged attempts to resolve completely preoperative respiratory infection would not be successful in the presence of significantly increased pulmonary blood flow. This strategy was successful in 11 of 12 infants who became candidates for corrective cardiac surgery after admission. Among the 8 infants who did not undergo surgical intervention during admission, 5 presented in an advanced state of illness, deteriorated rapidly, and died within hours. Only one infant (Table 1, patient 18) was discharged without surgical intervention; this patient subsequently underwent palliation with a pul- monary artery band instead of a corrective operation because she had multiple apical muscular VSDs.

In spite of relatively longer postoperative recovery times, our overall results demonstrate the feasibility of corrective cardiac surgery in these critically ill infants. This has important implications. Corrective surgical intervention can salvage these infants from their critical illness. In addition, corrective surgical intervention offers improved odds of freedom from hospitalization from recurrent respiratory infections, as well as early normalization of growth. Children living far from the equator are placed at significant risk if allowed to continue unrepaired into winter, when viral respiratory infections are most common.

Postoperative recovery times for the group of ventilated patients were significantly longer than in those undergoing elective repair (Table 2). Delayed sternal closure, pulmonary hypertensive crises, reintubation, and additional time to recover lung function all contributed to prolonged postoperative recovery time.

Corrective cardiac surgery on these critically ill children creates a significant economic burden in the developing world. Among the patients in this series who underwent cardiac surgery, the average additional cost was $67 \%$ higher than for elective operations for the same cardiac diagnosis, primarily because of the prolonged postoperative recovery time. Preoperative lung infection and mechanical ventilation are well-recognized risk factors for higher costs in congenital heart operations. ${ }^{22}$

The chief argument favoring a pulmonary artery band for ventilated infants with VSD (the third strategy above) is the avoidance of $\mathrm{CPB}$. This potential advantage must be weighed against both the challenge of determining the appropriate tightness of a pulmonary artery band in the setting of increased PVR from respiratory infection and the requirement of a future corrective operation. Although an interventional catheterization to occlude selected muscular VSDs would also avoid CPB, few infants would be acceptable candidates.

\section{Timing of the Corrective Operation}

The decision on timing of the operation for these patients is a critical one. We used simple clinical indicators to determine the patient's fitness for cardiac surgery. These included the absence of fever for more than 48 hours; improvement in total white blood cell counts, platelet counts, or both; some reduction of lung infiltrates on chest radiographs; and improvement in gas exchange. Complete resolution of pneumonia on the chest radiograph was not an absolute requirement (Figure 2). Serial bedside color Doppler echocardiography also played a significant role. Alveolar hypoxia from lung infection contributes to transient increase of PVR, resulting in bidirectional or right-to-left shunting 


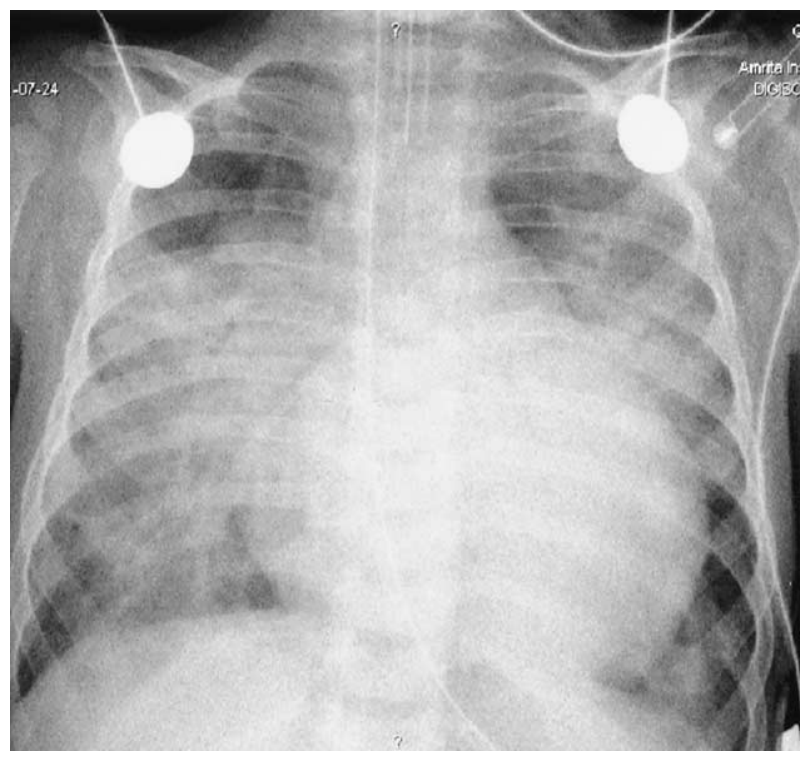

Figure 2. Typical chest radiograph of one of the study patients just before surgical intervention. Complete resolution of lung parenchymal shadows was not considered necessary before the corrective operation.

across the defects. Six patients who underwent repair had predominant right-to-left shunting on color Doppler echocardiography at the time of admission. In all 6, as lung function improved, serial echocardiograms demonstrated a change to left-to-right shunting. We believe that it is important for patients to revert to left-to-right shunting across their defect or defects before proceeding to surgical repair. Interestingly, 2 of these 6 patients had episodes of severe pulmonary hypertension postoperatively, but these were all successfully managed. None of the patients undergoing operations had evidence of residual pulmonary hypertension at discharge.

\section{Study Limitations}

This is a retrospective study, and it therefore has inherent limitations. The number of infants we describe is small. No randomized control group for the patients undergoing surgical intervention exists. It would be difficult to perform a prospective, randomized clinical study to determine the optimal management strategy for these critically ill patients. Although the feasibility of corrective surgical intervention in this subset of infants is demonstrated here, management of these patients is resource intensive, and not all centers in the developing world are suitably equipped to pursue this strategy. Only bacterial pathogens were assessed. Therefore the approach we are recommending might not apply to all patients with lower respiratory tract infections (eg, respiratory syncytial virus pneumonia).

\section{Conclusions}

This study demonstrates the feasibility of corrective cardiac surgery in critically ill, mechanically ventilated, and malnourished infants with large left-to-right shunts. In spite of relatively high mortality, longer postoperative recovery times, and higher costs compared with those of patients undergoing elective repair, corrective cardiac surgery should be considered at the earliest opportunity because it might offer the best chance for a good outcome. Frequent clinical evaluations and laboratory testing, along with serial bedside echocardiograms, are useful for assessing the status of cardiorespiratory function and identifying the earliest appropriate time for surgical intervention.

\section{References}

1. Bernstein D. Epidemiology of congenital heart disease. In: Behrman RE, Kleigman RM, Arvin AM, editors. Nelson textbook of pediatrics. 15th ed. Philadelphia: W.B. Saunders \& Company; 1996. p. 1286.

2. Stanger P, Lucas RV Jr, Edwards JE. Anatomic factors causing respiratory distress in acyanotic congenital heart diseases. Pediatrics. 1969; 43:760-9.

3. DiCarlo JV, Steven JM. Project Hope, Children's Hospital, Moscow, Russia. Respiratory failure in congenital heart disease. Pediatr Clin North Am. 1994;41:525-42.

4. Salzer HR, Haschke F, Wimmer M. Growth and nutritional intake of infants with congenital heart disease. Pediatr Cardiol. 1989;10:17-23.

5. Demling RH, Truman R, Lind LJ, et al. Incidence of morbidity of extubation failure in surgical intensive care unit patients. Crit Care Med. 1988;16:573-7.

6. Bandla HPR, Hopkins RL, Beckerman RC, Gozal D. Pulmonary risk factors compromising postoperative recovery after surgical repair for congenital heart disease. Chest. 1999;116:740-7.

7. Kanter RK, Bove EL, Tobin JR, et al. Prolonged mechanical ventilation of infants after open-heart surgery. Crit Care Med. 1986;14:212-4.

8. Aldrich TK, Prezant DJ. Indications for mechanical ventilation. In: Tobin MJ, editor. Principles and practice of mechanical ventilation. 1st ed. New York: McGraw Hill Inc; 1994. p. 155-89.

9. Tobin MJ, Alex CG. Discontinuation of mechanical ventilation. In: Tobin MJ, editor. Principles and practice of mechanical ventilation. 1st ed. New York: McGraw Hill Inc; 1994. p. 1177-206.

10. de Leval M. Ventricular septal defects. In: Stark J, de Leval M, editors. Surgery for congenital heart defects. 2nd ed. Philadelphia: W.B. Saunders \& Company; 1994. p. 358-61.

11. The Warm Heart Investigators. Randomized trial of normothermic versus hypothermic coronary bypass surgery. Lancet. 1994;343:559-63.

12. Naik SK, Knight A, Elliot MA. A prospective randomized study of a modified technique of ultrafiltration during pediatric open-heart surgery. Circulation. 1991;84(suppl 5):III422-31.

13. Freely TW, Hedley-Whyte J. Weaning from controlled ventilation and supplemental oxygen. N Engl J Med. 1975;292:903-6.

14. Guerina N. Bacterial and fungal infections. In: Cloherty JP, Stark AR, editors. Manual of neonatal care. 3rd ed. Boston: Little Brown and Co; 1991. p. 157-8.

15. Hamill PVV, Drizd TA, Johnson CL, Reed RB, Roche AF. NCHS growth curves for children birth-18 years. United States. Vital Health Stat 111977 Nov (165):i-iv, 1-74.

16. Vaidyanathan B, Roth SJ, Rao SG, Gauvreau K, Shivaprakasha K, Kumar RK. Outcome of ventricular septal defect repair in a developing country. J Pediatr. 2002;140:736-41.

17. Markewitz A, Faist E, Lang S, et al. An imbalance in T-helper cell subsets alters immune response after cardiac surgery. Eur J Cardiothorac Surg. 1996;10:61-7.

18. Markewitz A, Faist E, Weinhold C, et al. Alterations of cell mediated immune response following cardiac surgery. Eur J Cardiothorac Surg. 1993;7:193-9.

19. Ramsay JG. The respiratory, renal and hepatic systems. Effects of 
cardiac surgery and CPB. In: Mora CT, editor. Cardiopulmonary bypass. Principles and techniques of extra corporeal circulation. 1st ed. New York: Springer; 1995. p. 147-57.

20. Khongphatthanayothin A, Wong PC, Samara Y, et al. Impact of respiratory syncytial infection on surgery for congenital heart disease. Postoperative course and outcomes. Crit Care Med. 1999;27:1974-81.
21. Zucker HA. The airway and mechanical ventilation. In: Chang AC, Hanley FL, Wernovsky G, editors. Pediatric cardiac intensive care. Baltimore: Williams and Wilkins; 1998. p. 95-106.

22. Ungerleider RM, Bengur AR, Kessenich AL, et al. Risk factors for higher costs in congenital heart operations. Ann Thorac Surg. 1997; 64:44-8.

\section{Targeted}

The Journal of Thoracic and Cardiovascular Surgery gives you two tables of contents.

The condensed table of contents tells you at a glance what topics and authors are presented each month. The expanded table of contents gives you a brief abstract of each article. You select only those articles of most interest to you for further reading. 